\title{
On Translating Andersen for Odia Readers: A Study of Biswa Sahitya Granthamala
}

\section{OPEN ACCESS}

Manuscript ID:

ENG-2020-08033174

Volume: 8

Issue: 3

Month: June

Year: 2020

P-ISSN: 2320-2645

E-ISSN: 2582-3531

Received: 26.04 .2020

Accepted: 21.05.2020

Published: 02.06.2020

Citation:

Ganguly, Sonali, et al.

"On Translating Andersen

for Odia Readers: A

Study of Biswa Sahitya

Granthamala." Shanlax

International Journal

of English, vol. 8, no. 3, 2020, pp. 19-25.

DOI:

https://doi.org/10.34293/

english.v8i3.3174

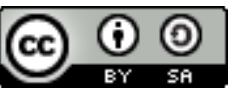

This work is licensed under a Creative

Commons Attribution-

ShareAlike 4.0

International License

\author{
Sonali Ganguly ${ }^{1}$, Lipika Das ${ }^{2} \&$ Tanutrushna Panigrahi ${ }^{2}$ \\ ${ }^{1}$ Research Scholar, ${ }^{2}$ Assistant Professor \\ International Institute of Information Technology, Bhubaneswar, Odisha, India \\ https://orcid.org/0000-0003-1493-9556
}

\begin{abstract}
The paper intends to study the translation of a few selected stories of Hans Christian Andersen in an Indian vernacular language, Odia. It argues that the translation strategy adapted by the translator is guided by the purpose of translation and the expectation of the target readers. The paper takes into account eight selected fairy tales translated by Sri. Sujata Mishra for this study, which is published under the Biswa Sahitya Granthamala series by Granthamandir, a renowned Indian publisher. We would examine the translation strategies used in introducing the world author to the non-English speaking readers of Odisha, an Indian state.
\end{abstract}

Keywords: Fairytale, Translation, Adaptation, Reception.

\section{Introduction}

Anderson is a Danish author. His literary excellence is appraised in Denmark as a great literary figure who developed the fairy tale genre and the language of literature. In England, he has been placed as a popular children's author. $\mathrm{He}$ experimented with several genres, such as poetry, autobiographies, novels, and stories that left his footprints amongst all. He is best known for his fairy tales. He had authored one hundred and fifty-six fairy tales, eighteen plays, four poems, fourteen novels and short stories, eight travel descriptions, and three autobiographies. According to the calculation of the Hans Christian Andersen Center in Odense, Denmark, his works have been translated into more than one hundred and fifty languages that straight away landed him in the world literary forum. The first collection of his fairy tales was published in 1835 titled Fairy Tales: Told for Children. Although, he subtitled the collection of stories as "told for children," he made it clear that he kept the door open for the adults. $\mathrm{He}$, in his journal, specified his intention to address the dual readership and not limit his tales to children. In his words:

"I said (...) that my tales were just as much as for grown-ups as for children, who only understood the story and did not comprehend and take in the whole work until they were mature." (1975: Vol X, 458)

He stated in one of his letters to B.S. Ingemann that he wrote the stories in the way he would have preferred to say to the listeners (Oster 2014:145).

It is interesting that the tales, addressed for dual readership, were adapted as children's literature, earning him the stature of children's author in the world. His stories received appreciation more in England than in Denmark because the genre of children's literature was established in England in the 19th century. His tales have been rewritten in Danish and has been translated into English by several authors. 
Anette Oster made a study of the translations of Andersen's fairy tales and ascertained that the translations of these tales are linguistically simpler and more sentimental than the original tales written in Danish. He further stated that Andersen was quite disappointed with the German translation of his tales, which lost the essence of the original text. He further requested Mary Howitt to maintain the originality in the form. He further expected that English, with all its sophistication, would do justice to his work (Oster 2014:142). The translators claimed that the translations are basically from the original text, but most of them also followed the German translation. Erik Haugaard also translated the tales of Andersen, which maintained proximity with the original text. The assessment of the translated version mostly depends upon whether it is a direct translation or an adaptation; the translation has taken the original book or the second language as the source. The text loses something when it gets translated.

During the nineteenth century, Andersen was translated into several world languages. Pederson (2004) asserted that these translations into world languages earned Andersen enormous popularity in the Eng-speaking world. In this context, Granthamandir, a renowned Indian publisher, attempted translating Andersen for the Odia readers and make them familiar with the fairy tales of the world. The unique attempt to translate him in a vernacular language did not intend to domesticate the author as an Indian storyteller, nor was the intension to demonstrate the gains and losses in the Odia translation. It was not meant for critical comparative analysis to assess the fidelity to the original text. The objective was to introduce the Danish author to the new readers and simplify the stories for better comprehension. It is to be made clear that simplification is not to domesticate his stories, instead, to make it accessible for the target readers in an Indian provincial state, Odisha.

In an attempt to simplify, there are glimpses of manipulations made in the plot to meet with the expected outcome that we shall discuss later. The critics opined that the translation could never do justice to the source text completely, how much consciously it might have been written. The world literature expert, David Damrosch, stated that world literature gains in translation; in a sense, it gains immense popularity as it crosses the geographical, cultural, and linguistic boundary of its origin and claims its position in the world literature. He was also not indifferent towards the negative impact of translation as he further stated, "in translation, we gain world literature, but lose the author's soul." The question, whether we lose something in translation, was addressed by Nicolas Harrison in his work. He mostly emphasized source language acquisition to be in a better position to make a qualitative assessment of a translation. For instance, the judgment of the English translation of Andersen's fairy tales would be incomplete without a textual, linguistic, cultural, thematic comparison with the source text. The situation complicates if the translation is made from another second language translation such as German, which demands the authenticity of the text with the original Danish version. The text, while passing through several hands of translation, not only gets interpreted, transformed, but also rewritten as per the expectation of the target culture and target readers. The real essence withers away in the process. In this critical context, we do not intend to judge several translations of Andersen's fairy tales. The purpose of our study is to examine the Odia translation of his eight selected tales and explore its contribution to the making of World Literature in Odia.

Before proceeding to discuss the fairytales of Andersen in Odia translation, we need to have a glance at the publication series, which accommodates the book.

\section{Anderson's Fairy Tales in Biswa Sahitya Series}

Biswa Sahitya Granthamala is a children's world literature series published by Granthamandir, a renowned Indian publishing house based at a provincial state, Odisha. It is a non-profit publishing house that launched the series in the mid-nineteenth century. The series included one hundred and eightyseven world literary texts from across the globe in Odia translation. Biswa Sahitya Granthamala intended to project the ancient and modern world literary pieces to the non-English speaking readers of Odisha. In addition to the primary concern for moral education and character building of target readers, attention is also on monitoring the growing 
adaptability of a child to assimilate and adequately respond to the global culture.

There is no explicit reference to the source text. Still, the publisher, Mr. Manoj Mahapatra, in a personal interview, hinted at the Macmillan books that flooded the Odishan market in the initial phase of the twentieth century. The contemporary translation tradition of Odisha confirmed that these are indirect translations. Mr. Mahapatra confirmed that the translators relied on the English version of Andersen's tales published by Macmillan as the ST. Hence, it is 'translation of translation' or 'retranslation.' The indirect translation is also termed as 'secondhand translation' (Toury, 1955), 'relay translation' (Dollerup 2000), or 'mediated translation' (Pym 2011). Lack of competent translators with mastery in the original language is the primary cause of adopting indirect translation. It also hints at another essential aspect, i.e., the dominating position of English as a mediating language. Heilborn perceived a centerperiphery relationship in this context (1999: 435). The center-dominated literary circulation allowed English to continue as a donor language.

The cultural distinction between the ST and the TT demands a thorough analysis of the target audience and the publication objectives. This cultural difference demanded textual manipulation, cultural adaptation, and information change in the target text to fit into the frames of children's world literature in Odia language. The textual manipulation and information change in the TT hinted at the translator's understanding of 'child image' and the concept of childhood in the target culture (TC). The TC was conscious of educating children and preparing them to accumulate with the world culture. The translation approach was based on the following perceptions:

Which stories could be translated for the children?

What impact will the story have on the readers? How would the children react to the stories?

What is the level of receptivity of the readers?

The above factors determined the translation strategy. Sri. Sujata Mishra made the Odia translation of Andersen's fairytale in 1978. The book titled 'Andersenka Pari Kahani' runs to sixty-four even pages and consists of eight selected stories of the world author. The eight selected tales of Andersen are - The Snow Queen (1845), The Flying Trunk (1838), The Wild Swans (1838), The Top and the Ball (1838), The Emperor's New Clothes (1844), The Nightingale (1844), The Red Shoes (1845), and The Garden of Paradise (1838). The titles of the stories are translated as - Barafa Desha Ra Rani, Udanta Sinduka, Rajakumari O Aegaarati Hansha, Natu O Balloon Kahani, Pagala Raja, Asli O Nakli Bulbul, Lal Joota, Swargara Udyaan, respectively.

The translated titles of the stories display different strategies. The title, The Snow Queen, keeps the door open for imagination that the queen is probably made of snow. The translated title 'Barafa Deshara Rani' makes it clear that she is the queen of the country of snow. This is the example of an explanatory translation that carries the readers one step ahead in imagining the country of snow and hints at the settings and events to follow. The Wild Swans is translated as 'Rajakumari O Egarahati Hansha.' The literal translation would have been 'Jungali Hansha' or 'Hansha,' but the translator tried to be descriptive and introduced the major characters in the title. The English title emphasized only the Swans, whereas the translator added the princess too in the title, without whom the plot remains incomplete.

Similarly, the accurate translation of the title The Emperor's New Clothes would have been 'Maharajakara Nutana Posaka', but the title aims at characterizing the protagonist and translated as 'Pagala Raaja' (Lunatic King). The Nightingale in Odia is termed as 'BulBul.' Instead of this one-word translation, the translator expanded it to 'Asli O Nakli Bulbul' (The Original and Fake Nightingale). The theme of the story is highlighted in the translated title. The translated titles focused either on the characters or theme of the story; hence, it appeared explanatory. Other Odia titles are literal translations, such as in The Red Shoes and The Garden of Paradise, we only find the translation of lexical words like Red as Laal, Shoes as Jotaa, Garden as Udyaan and Paradise as Swarga. The word order is changed in the last name as per the target language grammatical structure. A close reading of these eight stories, both in English and Odia translation, revealed several interesting facts and choice of specific translation strategies. A literal translation is preferred with a little 
manipulation, keeping the target readers in mind. The settings, characters, events remain unchanged with some notable changes towards the end of some stories.

The target audience received immense attention from the translator, which resulted in textual manipulation. There are information changes, omissions, and additions in the TT to meet with the reader's expectation, publication objective, and better reception of the stories as children's literature. The English adaptations are made to fit with the traditional fairy tale mold (Oster 2014:147). Similar adjustments are made to culturally adjust the tales into the frame of Odia world literature. The opening line of all the stories remains conventional - 'once upon a time' phrase, which is hardly used by Andersen. The translator also maintained the same style of using a conventional opening in all the eight stories. The opening lines of the stories along with the translations of the same are mentioned below:

Aneka Dina tale jane Jaadugara Thila, (Barafa Desha Ra Rani)

(Once upon a time, there was a magician)

Jane dhani mahaajana thila (Udanta Sinduka)

(There was a rich merchant)

Jane raja thila (Raajakumari $\boldsymbol{O}$ Aegaarati

Hansha)

There was a king.

Ask khelanaa bakasha re gote natu o gote balloon thila (Natu O Balloon ra Kahani)

There was a top and a ball in a box.

Bahu dina tala ra kaatha (Pagala Raja)

Once upon a time...

Bahut dina tale Chin desha re jane raja thile

\section{(Asli O Nakli Bubul)}

Once upon a time, there was a king in China.

Koren boli Sundari Jhia tiye thila (Lal Joota)

There was a beautiful girl named Coren.

Bahut dina tale jane rajkumar thile (Swargara

\section{Udyaan)}

Once upon a time, there was a prince.

The Odia translation marks significant changes in some of the stories. For instance, in the ending of The Flying Trunk and the Garden of Paradise. In the original story of The Flying Trunk, the merchant and the princess were never married. The flying trunk burns into ashes due to the spark of the fireworks.
He could neither fly to the princess, nor could get married, instead, he wonders everywhere telling fairy tales, and the princess keeps waiting for him. In the translation, the merchant and the princess get married and live happily after that. It presents the flying trunk as a magical medium that brought lots of happiness in their life, but this is a mismatch with the English translation. The episode of the fireworks and the trunk burning into ashes is omitted in the Odia translation. The first version gave a moral message that 'one has to pay for lies' whereas the translator provided the message that the magical trunk united the couple and showered happiness in their life. Mishra preferred a happy ending of the stories because complication or unhappy ending in children's literature makes no sense. This is an example of information change. Similarly, in the story The Garden of Paradise, the prince meets an older man, having strong physic, large wings, and a scythe in his hand whose name is death. He warns him to atone for his sin and get a chance to visit the garden of paradise in a world beyond the stars after death. The story ends with the message that if the heart is pure, one gets into the garden; if the heart is full of sin, one sinks into the darkness of hell. This episode is missing in the Odia adaptation. The prince finds himself in the cave after the fall of heaven, and the old lady advises him to change himself. The omission intends to avoid the complicated discussion of the Biblical concepts like the fall of Paradise, sin, temptation, heaven, and hell phenomena which do not exist in the target culture. The story ended with a moral that one needs mental purity to realize eternal beauty. Considering the harshness of the climax and the impact of the message on the target readers, the translator chose an alternative ending. Changes were made in the stories without a happy ending, and too many shades of meaning. The Odia translations ended with an optimistic note. The Snow Queen also had several changes in its opening and the closing sections. Close reading makes clear that addition of information or the changes made at the end of the stories, takes into account the target readers.

The prominence of cultural adaptation and textual manipulation in children's literature is for ideological purposes (Shavit, 1981). In this context, textual manipulation and information change result 
in complete modification of a few sections of the ST. The fidelity is compromised to retain ideological values. For instance, sexual overtones and irony have been removed. In the English translation of The Snow Queen, the reference to the queen kissing Kay that is represented as:

ST: The Snow Queen kissed him on the forehead.

TT: Barafa rani Kay mundare hatha bulaedele. (Barafa Desha ra Raani, P-8, BSG)

(The snow queen caressed Kay) (My Translation)

Similarly, in the Garden of Paradise, the reference to the prince kissing the fairy, being tempted by her beauty:

ST: He stooped and kissed the tears from her eyes and touched her lips with his.

TT: Rajakumaar Aagaku Jae taku chuedele. (Swargara Udyaan, p-64, BSG)

(The prince stepped ahead and touched the fairy) (My Translation)

Both examples narrate the scene of kissing. In the first example, 'kissing' is replaced with 'Caressing,' and in the second, passionate moves of the prince are not elaborated. It is limited to 'touch,' and the mention of 'kiss' is avoided.

The references to the fairy taking off her dazzling attire and the descriptive passage on tempting the prince are also deliberately omitted in the TT. Omission, in this context, assisted in removing the unnecessary ideological confrontation in the TT. Information change is also noticed in 'The Emperor's New Clothes.' The English version of the text referred to 'theatre' as the emperor's favorite amusement, which is culture-specific. The emperor in the TT spent time in hunting. Theatre was not prevalent in Odisha. So, it is replaced. Cultural adaptation is also marked in the 'Garden of Paradise.' When the old lady in the large cave referred to her sons:

ST: My sons are the four winds of heaven. They are playing a shuttlecock with the clouds up yonder in the king's hall.

TT: Bartamaan, semaane Indra raja ka khelapadiyaa re megha sahita ball kheluchanti (Swargara Udyaan, p-57, BSG)

(At present, they are playing ball with the clouds in the playground of King Indra)

(My Translation)
In the above example, the king is changed to 'Indra Raja, ' the king of heaven, according to Hindu mythology. The reference to shuttlecock is translated as 'ball,' which is not an equivalent alternative. The shuttlecock is a feathered cork used to play badminton, whereas the ball has a different structure and is used for different games. The target readers are more familiar with the ball than a shuttlecock.

In keeping with Granthamandir's commitment towards bringing the world literary texts closer to the non-English speaking readers of Odisha, Mishra used local equivalents for specific nouns that could not be directly translated. For instance, in the story The Garden of Paradise, she used 'Timi' (Whale Shark) for Walrus. Walrus is compared with a Tiger. It is a large marine mammal having a long pair of teeth. The North Wind refers to the Walrus several times while narrating his experience in Bear Island, and the translator referred to different sea animals such as Sea-Horse (Samudra-Ghoda), and Whales (Timi). The English translation refers to the 'wicked sprite' in the opening chapter (The Snow Queen), whereas the Odia translation uses the term Jaadugara. The literal meaning of the two does not mean the same. The term 'sprite' means an elf, having small wings connected with water, but, Jaadugara refers to a magician. The term 'fur' is used to describe the long covering wore by the snow queen, which is translated into Odia as chaadara means a shawl. The fur refers to the skin of an animal used to cover the body in the winter season, and the two terms fur and chaadara are not semantic equivalents. The cultural and linguistic expressions and the target culture are taken into consideration while representing the words and events in the TT. The unavailability of the equivalent words made the translator stick to a few English terms such as magic, sledge, and Phoenix. The translator tactfully introduced the term 'sledge' as 'gaadi... barafa up are khasibaara khela that means 'a vehicle used to slide in the snow.' This is an example of explanatory translation. It is also used in The Garden of Paradise. For instance:

ST: The harpoon was flung into the breast of the Walrus. (The Garden of Paradise)

TT: Gotiye bada kanta Samudra-Ghodara chhatire lagila. (Swargara Udyaana, P-58, BSG) 
(A big spear hit the breast of the Sea-Horse) (My Translation)

The word harpoon is termed as 'gotiye bada kanta' (a big spear), which explains the structure of the weapon but is not the literal translation of the word. We find other culture-specific references to add clarity in the TT such as the snow queen is referred as Devi means Goddess like figure, Angel is replaced with Debaduta (messenger of God), Swarga ra Debata means the heavenly God, Death is translated as 'Mrutyu Debata' means the death God. Aurora Borealis or the reddish light in the sky indicating the dawn is represented as Merujyoti (The Snow Queen), and Polar Seas is referred to as Dhrubatara (The Garden of Paradise). It can be considered as partial domestication meant for emphasizing the cultural aspects to maintain the real essence of the story. The foreign flavor adds to the reader's understanding of the foreign culture. The proper nouns as Kay, Gareda (The Snow Queen), Karen (The Red Shoes), Eliza (The Wild Swans) remain unchanged. There are references to several foreign lands in all the stories that remain unchanged. For instance, in The Snow Queen, there is a reference of Lapland and Finland, The Flying Truck lands the protagonist at Turkey, The Nightingale relates to a story from China, the West wind referred to America, South wind referred to Africa, and the East Wind referred to China. Some exceptions are noticed in The Garden of Paradise, where Mishra translated 'the Island of Happiness' as 'Soubhagya Dweepa' (Fortune Island). Klingberg advocated the rendition of geographical settings in the translations (Klingberg, 1956). The readers, in this form, visualize the foreign location where the events took place.

The plot movement in Andersen's tales leaves the message at the end of the story. Each story in the end transformed the protagonist, teaching some valuable lessons. The choice of stories to be included in Andersen ka Pari Kahani under the Biswa Sahitya series was made with an expectation to find similar transformations within the readers. The translator followed the principle that children should learn values and manners but not as lessons but in a fun mode in the form of exciting stories where they could place themselves as the chief protagonist and visualize the repercussions. The language used in translation is simple, devoid of any ornamental words or irony of the original Andersen fairy tales.

\section{Conclusion}

The English translation of his work has earned him the recognition of a world author and, more specifically, as a children's author, but Andersen never limited his stories to children. Instead, he expected adults to follow the inherent message. Elias Bredsdorff opined that the poor translations had given a distorted, one-sided view of Anderson to the English speaking world. His deserving status has been deprived as they hardly succeed in identifying the artistic intelligence that he possesses. The Odia version retained the storyline, but cannot be considered as a pure translation as it involved omission and modification of the original text. It presented Andersen to the target readers, as a literary figure of Denmark, who established the genre of children's literature. Mishra in translating Hans Andersen abided by the publication objective and followed the target-reader oriented translation strategies. The foreign element is retained in the proper names and geographical locations. She used cultural adaptation, information change, omission, and explanatory translation to adjust the TT within the frames of children's literature in Odia. The literal translation of the story with changes at the end met with the publication objectives. Andersen ka Pari Kahani is the perfect representation of world literature in Odia language. Furthermore, the fulllength translation of his tales would add to his stature in the non-English speaking countries.

\section{References}

Andersen's Fairy Tales, translated by Sujata Mishra, Granthamandir, 1978.

Damrosch, David. What is World Literature? Princeton University Press, 2003.

Damrosch, David. World Literature in Theory. John Wiley \& Sons, 2014.

Dollerup, C. "Relay and Support Translations." Translation in Context: Selected Contributions from the EST Congress, Granada, 1988, edited by Chesterman, Andrew, et al. John Benjamins, pp. 17-26 
Heilbron, J. "Towards a Sociology of Translation. Book Translations as a Cultural WorldSystem.” European Journal of Social Theory, vol. 2, no. 4. 1999, pp. 429-444.

Klingberg, G. Children's Fiction in the Hands of the Translators. CWK Gleerup, 1986.

Klingberg, G. et al. Children's Books in Translation: the Situation and the Problems. Almqvist and Wiksell International, 1978.

Lathey, G. The Translation of Children's Literature: a Reader. Multilingual Matters, 2006.

Oittinen, R. Translating for Children. Garland, New York, 2000.

Oster, Anette. "Hans Christian Andersen's Fairy Tales in Translation." Children's literature in Translation: Challenges and Strategies, edited by Coillie, Jan Van and Walter P. Verschueren, Routledge, 2006.

Pedersen, Viggo Hjornager. Ugly Ducklings?Studies in the English Translations of Hans Cgristian Andersen's Tales and Stories, University Press of Southern Denmark, 2004.

Pym, Anthony. "Translation Research Terms: A Tentative Glossary for Moments of Perplexity and Dispute." Translation Research Projects 3, edited by Pym, Anthony, Intercultural Studies Group, 2011, pp. 75-110.

Toury, G. Descriptive Translation Studies and Beyond. John Benjamins, 1995.

\section{Author Details}

\section{Sonali Ganguly ${ }^{1}$, Dr. Lipika Das ${ }^{2} \&$ Dr. Tanutrushna Panigrahi ${ }^{2}$}

${ }^{1}$ Research Scholar, ${ }^{2}$ Assistant Professor,

International Institute of Information Technology, Bhubaneswar, Odisha, India

Email ID: sona.ganguly88@gmail.com,lipika@iiit-bh.ac.in\&tanutrushna@iiit-bh.ac.in 